\title{
Nucleotide Sequencing and Identification of Some Wild Mushrooms
}

\author{
Sudip Kumar Das, ${ }^{1}$ Aninda Mandal, ${ }^{1}$ Animesh K. Datta, ${ }^{1}$ Sudha Gupta, ${ }^{2}$ Rita Paul, ${ }^{3}$ \\ Aditi Saha, ${ }^{4}$ Sonali Sengupta, ${ }^{5}$ and Priyanka Kumari Dubey ${ }^{1}$ \\ ${ }^{1}$ Cytogenetics, Genetics and Plant Breeding Section, Department of Botany, Kalyani University, Kalyani, West Bengal 741235, India \\ ${ }^{2}$ Pteridology-Palaeobotany Section, Department of Botany, Kalyani University, Kalyani, West Bengal 741235, India \\ ${ }^{3}$ Department of Botany, Charuchandra College, Kolkata, West Bengal 700029, India \\ ${ }^{4}$ Department of Botany, Narasinha Dutt College, Howrah, West Bengal 711101, India \\ ${ }^{5}$ P.G. Department of Botany, Hooghly Mohsin College, Hooghly, West Bengal 712101, India
}

Correspondence should be addressed to Animesh K. Datta; dattaanimesh@gmail.com

Received 26 August 2013; Accepted 14 October 2013

Academic Editors: X. Liang and J. Yoon

Copyright (c) 2013 Sudip Kumar Das et al. This is an open access article distributed under the Creative Commons Attribution License, which permits unrestricted use, distribution, and reproduction in any medium, provided the original work is properly cited.

The rDNA-ITS (Ribosomal DNA Internal Transcribed Spacers) fragment of the genomic DNA of 8 wild edible mushrooms (collected from Eastern Chota Nagpur Plateau of West Bengal, India) was amplified using ITS1 (Internal Transcribed Spacers 1) and ITS2 primers and subjected to nucleotide sequence determination for identification of mushrooms as mentioned. The sequences were aligned using ClustalW software program. The aligned sequences revealed identity (homology percentage from GenBank data base) of Amanita hemibapha [CN (Chota Nagpur) 1, \% identity 99 (JX844716.1)], Amanita sp. [CN 2, \% identity 98 (JX844763.1)], Astraeus hygrometricus [CN 3, \% identity 87 (FJ536664.1)], Termitomyces sp. [CN 4, \% identity 90 (JF746992.1)], Termitomyces sp. [CN 5, \% identity 99 (GU001667.1)], T. microcarpus [CN 6, \% identity 82 (EF421077.1)], Termitomyces sp. [CN 7, \% identity 76 (JF746993.1)], and Volvariella volvacea [CN 8, \% identity 100 (JN086680.1)]. Although out of 8 mushrooms 4 could be identified up to species level, the nucleotide sequences of the rest may be relevant to further characterization. A phylogenetic tree is constructed using Neighbor-Joining method showing interrelationship between/among the mushrooms. The determined nucleotide sequences of the mushrooms may provide additional information enriching GenBank database aiding to molecular taxonomy and facilitating its domestication and characterization for human benefits.

\section{Introduction}

Mushrooms are defined as "a macro fungi with a distinctive fruiting body" [1] and are traditionally used worldwide as nutritious food and as medicinal sources [2-7] including antioxidant activity $[8,9]$. Further, mushrooms are great recyclers and decomposers [10] and therefore play a significant role in the ecosystem. To date, about 3000 species are regarded as prime edible mushrooms [11]. Proper identification knowledge of edible mushrooms is essential for effective exploration in human benefits.

Molecular markers, PCR (Polymerase Chain Reaction) [12] and non-PCR based [13], are widely used for mushroom identification and characterization. However, direct sequencing of PCR product of repetitive nuclear DNA [14-16] of mushrooms is powerful tool for identification and phylogenetic studies [17]. The present study describes the nucleotide sequencing of 8 wild edible mushrooms collected from Eastern Chota Nagpur Plateau of West Bengal, India, using genomic DNA from fruit bodies. The rDNA-ITS (Ribosomal DNA Internal Transcribed Spacers) fragments of the genomic DNA were amplified using ITS1 (Internal Transcribed Spacers 1) and ITS2 primers. The nucleotide sequences of 8 mushrooms were matched from the available known sequences of GenBank database. The ITS region is rather useful for molecular characterization in fungi at the species level and within the species [11]. The objective of the work is to gain proper identification knowledge of the mushrooms, 
TABle 1: Primers designed for different mushroom sample amplification.

\begin{tabular}{|c|c|c|c|c|c|}
\hline Sl. no. & Primer name & Sequence $\left(5^{\prime}\right.$ to $\left.3^{\prime}\right)$ & Size (bp) & Melting temp. $\left({ }^{\circ} \mathrm{C}\right)$ & Amplicon size (bp) \\
\hline 1 & Len-F & TGGTTACTCTACAAACACTT & 20 & 54 & \\
\hline 2 & Len-R & CCTGCTAATGTATTTCAGAAG & 21 & 58 & 331 \\
\hline 3 & Vol-F & GATCATTACAGAATCGAACGC & 21 & 60 & \\
\hline 4 & Vol-R & CTGGGCTTGAGGATTCGATG & 20 & 62 & 290 \\
\hline 5 & Rus-F & AGTGCTCTCACATACAAATATC & 22 & 60 & \\
\hline 6 & Rus-R & GTTGAGGATGTTCACGACACTC & 22 & 66 & 290 \\
\hline 7 & Ter-F & GCAACGGCACTCTATCGCTGA & 21 & 66 & \\
\hline 8 & Ter-R & CTCCTCAGATCACCAAGGAG & 20 & 62 & 321 \\
\hline 9 & Ast-F & CTCCAACTTCATCAAGAAGGT & 21 & 60 & \\
\hline 10 & Ast-R & GATCTTGTAGACATCCTGGAGAG & 23 & 68 & 230 \\
\hline 11 & Ama-F & TCTTGGCTCTCGCATCGATG & 20 & 62 & \\
\hline 12 & Ama-R & CCAGCAATGACTCCCAATATC & 21 & 62 & 200 \\
\hline
\end{tabular}

which may provide direction towards domestication and commercialization of the wild species for economic benefits apart from aiding molecular taxonomy.

\section{Materials and Methods}

2.1. Germplasms. Eight morphologically different types of wild edible mushrooms (CN (Chota Nagpur) [1-8]) were collected from their natural habitat in Eastern Chota Nagpur Plateau of West Bengal (Paschim Medinipur having sandy loam to loamy soil of reddish brown color cover; latitude $22^{\circ} \mathrm{N}$ to $25^{\circ} 30^{\prime} \mathrm{N}$, longitude $83^{\circ} 47^{\prime} \mathrm{E}$ to $87^{\circ} 50^{\prime} \mathrm{E}$, altitude $610 \mathrm{~m}$ ) during the rainy (June-July) and postrainy (August to October) seasons of 3 consecutive years (2008 to 2010). The mushroom samples were characterized morphologically following the methodology suggested by Largent and Stuntz [18]. The samples verified up to genus level [19] were as follows: CN 1-Amanita sp.; CN 2-Amanita sp.; CN 3Astraeus sp.; CN 4-Termitomyces sp.; CN 5-Termitomyces sp.; CN 6-Termitomyces sp.; CN 7-Termitomyces sp.; and CN 8-Volvariella sp.

2.2. DNA Isolation. Field isolated samples were dried $\left(45^{\circ} \mathrm{C} \pm\right.$ $1^{\circ} \mathrm{C}$ ) and the dried samples were used for fungal DNA isolation from fruit bodies using the Fungal Genomic DNA MiniSpin Kit (Chromous Biotech, Bangalore) as per methodology suggested by Graham et al. [20]. Isolated DNA samples were checked in agarose gel (1\% agarose gel prepared in TAE (Tris-acetate-ethylenediaminetetraacetic acid) buffer to which $2 \mu \mathrm{L}$ ethidium bromide was added) to confirm the yield of DNA, purity, and concentration. A ladder ( $1 \mathrm{~kb}$ plus) was loaded in the gel in order to compare the size of the isolated DNA samples.

2.3. Primer Designing. Based on morphological identification of the samples, available nucleotide sequences ranging from 2 to $5 \mathrm{~kb}$ were downloaded from GenBank data base for primer designing. The FASTA format of all those sequences was arranged in a file and then the sequences were aligned according to their homology of nucleotide using ClustalW software program (http://www.ebi.ac.uk/Tools/msa/clustalw2/). The stretches of conserved sequences (ITS1 and ITS2) were considered for primer designing. The length of the primers was kept within 18 to $25 \mathrm{bp}$ and the GC\% was within 40 to $55 \%$ so that the melting temperature of the primers will not be high during PCR. It was also considered that the amplicon size should not cross more than 500 bp. Forward and reverse primers (Table 1) for 8 mushroom samples were synthesized commercially (IDT, USA) for amplification of fungal DNA.

2.4. PCR Reactions. Polymerase chain reaction was performed using the following: 10x PCR buffer $2.5 \mu \mathrm{L}$, dNTPs (25 mM of each) $2.0 \mu \mathrm{L}, \mathrm{MgCl}_{2}(25 \mathrm{mM}) 2.0 \mu \mathrm{L}$, forward primer $(10 \mathrm{pm} / \mu \mathrm{L}) 1.0 \mu \mathrm{L}$, reverse primer $(10 \mathrm{pm} / \mu \mathrm{L}) 1.0 \mu \mathrm{L}$, DNA template $10 \mathrm{ng}$ for each sample, Taq. polymerase $(2 \mathrm{U} / \mu \mathrm{L}) 0.5 \mu \mathrm{L}$, and DNase- and RNase-free water where volume was adjusted to $25 \mu \mathrm{L}$. The PCR conditions were determined according to Taq. polymerase, primer pair, and amplicon size. The amplification reactions were performed in a DNA Thermal Cycler (Eppendorf AG, Hamburg, Germany) programed as follows: 1st cycle of $5 \mathrm{~min}$ at $95^{\circ} \mathrm{C}$ (initial denaturation) followed by 30 cycles of $45 \mathrm{sec}$ at $95^{\circ} \mathrm{C}$ (denaturation), $30 \mathrm{sec}$ at $50^{\circ} \mathrm{C}$ (annealing), $1 \mathrm{~min}$ at $72^{\circ} \mathrm{C}$ (extension), and 1 cycle of $10 \mathrm{~min}$ at $72^{\circ} \mathrm{C}$ (final extension). The final step was held at $4^{\circ} \mathrm{C}$. The PCR products were stored at $-20^{\circ} \mathrm{C}$ and subsequently run in agarose (Hi-media, USA; in TAE buffer) gel $(1 \%)$. PCR product $(10 \mu \mathrm{L})$ was loaded in the gel by adding 6x DNA loading dye along with 2-log DNA ladder. The gel was run at 50 volts for 1 hour and the amplified products were visualized in the UV trans-illuminator and photographed in Gel Doc system (Bio-Rad, USA).

2.5. Sequencing. The PCR products were loaded in the coupled lane of low melting point agarose gel (Sigma, USA). The run was at 40 volts for 1 hour and the bands were cut using sterile blade. The DNA was extracted from the agarose using columns (QIAGEN, Germany). This DNA was quantified 
TABle 2: Partial nucleotide sequences of the field isolated mushroom samples.

\begin{tabular}{|c|c|}
\hline Sample number & Sequences \\
\hline $\mathrm{CN} 1$ & $\begin{array}{l}\text { TCTTGGCTCTCGCATCGATGAAGAACGCAGCGAAATGCGATAAGTAATGTGA } \\
\text { ATTGCAGAATTCAGTGAATCATCGAATCTTTGAACGCATCTTGCGCTCTTTGG } \\
\text { TATTCCGAGGAGCATGCCTGTTTGAGTGTCATTAATCTCTCAAAAACACTTG } \\
\text { GTTTTTGGATATTGGGAGTCATTGCTGG }\end{array}$ \\
\hline $\mathrm{CN} 2$ & $\begin{array}{l}\text { TCTTGGCTCTCGCATCGATGAAGAACGCAGCGAAATGCGATAAGTAATGTGA } \\
\text { ATTGCAGAATTCAGTGAATCATCGAATCTTTGAACGCATCTTGCGCTCCTTGG } \\
\text { CATTCCAAGGAGCATGCCTGTTTGAGTGTCATTAATATCTCAAAATACTTTAA } \\
\text { GTGTTTTGGATATTGGGAGTCATTGCTGG }\end{array}$ \\
\hline $\mathrm{CN} 3$ & $\begin{array}{l}\text { AACTGGAGGCTCGAGGCGTCGATGGCGTCAAGGAGCGTCTTGCCCTTGACAC } \\
\text { CGCTTTGGTTTCCTTAGTCCAGCCTTTGTACCATGGCATGCTATTCGGCGAGT } \\
\text { CAGGTTACGTAACAGAGATGAGATTAAAACGCGCACTTAGATGATTCCTCCA } \\
\text { ACATGTTGTCACCGTGCCATCCAGAGATGGGGACGAATGCAACAGCCTTGGG } \\
\text { GTTGTAACCGACCTTCTTGATGAAGTTGGAGAA }\end{array}$ \\
\hline $\mathrm{CN} 4$ & $\begin{array}{l}\text { AATTTTACCTTTATCACATTTCGCTGCATTCTTCATCAATGCCTTACCAAGAA } \\
\text { ATCTATTGCTGAAAGTTGTATTTGATTAAAGGCCTGAGGCCAATAACAAGAC } \\
\text { ATTCTAATACATTCTTTACAAAGTGATGAAATGCATAGACCAGAAATGCGAG } \\
\text { GAAAGCCAGTGGCAGCCCCTCAAAACTGAGAGTGTGACCCCCCAAAAGGTA } \\
\text { TCCAAAAGTCTACAAAAGGTGCACAGATGGTTGAAAATGATGGCAGGCGTG } \\
\text { CACATGCCCCTAGAGCCAGCAACAACCTGATCAGGTTTAATTCAATAATGAT } \\
\text { CTTTCTGCAGGTTCACTTACAAAAACCTTGTTACTATTTTACTTCCTCTAAAT } \\
\text { GACCAAGTTTGATCAGCTTCTCAGCGATAGAGTGCCGTTGCCTA }\end{array}$ \\
\hline CN 5 & $\begin{array}{l}\text { TGTATTTAGAGGAGTAAAGTCGTAACAAGGTTTCCGTAGGTGAACCTGCGGA } \\
\text { AGGATCATTATTGAATTTAAACCCTGGTTGGGTTGTTGCTGGCCTCTAGGGG } \\
\text { CATGTGCACGCCTGCCACCGTTTTCAACCACCTGTGCACCTTTTGTAGACTTT } \\
\text { GGATATATACCGTTCGAGGGTCAAACCCCCTCCTCGGTTTTGAGGGCTTGCT } \\
\text { GTGCTGCAAAGTTCGGCTTCCCTTGCATTCCCAGTCTATGCATCTTCCTATAC } \\
\text { CCCGTAATGAATGTATTAGAATGTTTTTTTATTGGCCTTTTTAGTGCCTTTAAT } \\
\text { CAAATACAACTTTCAGCAACGGATCTCTTGGCTCTCGCATCGATGAAGAACG } \\
\text { CAGCGAAATGCGATAAGTAATGTGAATTGCAGAATTCAGTGAATCATCGAAT } \\
\text { CTTTGAACGCACCTTGCGCTCCTTGGAGAACAGAAGGAGAAGA }\end{array}$ \\
\hline CN 6 & $\begin{array}{l}\text { TCGTACCCAAAGAAGGGATCGATCATACCATATTTTTAACAATTTTTGATGG } \\
\text { TTATTTTCAGCATGCATGGTACAAGGGTGGACCAAGGAGACCAAGGCTAGTG } \\
\text { TTTCAAGGCAAGACCCTTCACAAACCTTCATCCTTGACCCCCTTTCTCCATCA } \\
\text { AAAAAACTTAAAAG }\end{array}$ \\
\hline CN 7 & $\begin{array}{l}\text { ACCCTCCCCCAAACCAGGGTTTGGACCCCCCGGCCCGGATCCAAAACGGGG } \\
\text { GTTAAAAACAAGGGCGGGGGCCCTTGCCTCTAAAGGCCAACACCCCACCCG } \\
\text { GGTTTAATTCAAAAAGGACCCTTCCCAGGTTCCCCTACGAAAACCTTGTTCA } \\
\text { ACTTTTATTTCCCCAAAAACCAATTTTAACCTTTCCCCCAATAAAGGCCCTTT } \\
\text { ACCAA }\end{array}$ \\
\hline $\mathrm{CN} 8$ & $\begin{array}{l}\text { GATCATTACAGAATCGAACGCGGGTCGGGCTGATTGCTGGCTCCTCGGAGCA } \\
\text { GGTGCACGCCCTCCCCGACGCCTTCCATTCTCCACGTCCCCACCTGTGCACCT } \\
\text { TCTGTAGGCCGTGAAGCCGCCTCGTTCGGCTCCCTCGGCTCTACGAGATCTTT } \\
\text { TGTACACCCTTGAGAAAAACGTGTTGCAGAGTGTTCTTGTACGACCGGGGAC } \\
\text { CCCTCGTCGGCCCCATAGACATACCAATACAACTTTCAACAACGGATCTCTT } \\
\text { GGCTCTCGCATCGATGAAGAACGCAGCGAAATGCGATAAGTAATGTGAATT } \\
\text { GCAGAATTCAGTGAATCATCGAATCTTTGAACGCACCTTGCGCTCTTAGTAA } \\
\text { TGTGAATTGCAGAATTCAGTGAATCATCGAATCTTTGAACGCACCTTGCGCT } \\
\text { CTT }\end{array}$ \\
\hline
\end{tabular}

in $1 \%$ agarose gel and then sequenced using the respective forward and reverse primers. The kit which was used for DNA sequencing was Big Dye Terminator Kits, Applied Biosystems, USA and the sequencing was done in Capillary Electrophoresis DNA Sequencer, Applied Biosystems, USA.

2.6. Evolutionary Relationships Analysis. Following alignment of the nucleotide sequences, a phylogenetic tree was constructed using the Neighbor-Joining method [21]. The optimal tree is drawn with the sum of branch length equal to 1.4246 . The tree is drawn to scale, with branch lengths in the same unit as those of the evolutionary distances used to infer the phylogenetic tree. The evolutionary distances were computed using the Maximum Composite Likelihood method [22] and are in the unit of the number of base substitutions per site. The analysis involved 8 nucleotide 
TABLE 3: Summary of the BLAST result.

\begin{tabular}{|c|c|c|c|c|}
\hline Samples & $\begin{array}{c}\text { Sequence length } \\
\text { blasted (bp) }\end{array}$ & Highest coverage & $\begin{array}{c}\text { \% identity } \\
\text { (accession no.) }\end{array}$ & Identified name of samples \\
\hline $\mathrm{CN} 1$ & 185 & $100 \%$ & 99 (JX844716.1) & Amanita hemibapha \\
\hline $\mathrm{CN} 2$ & 187 & $100 \%$ & 98 (JX844763.1) & Amanita sp. \\
\hline CN 3 & 250 & $95 \%$ & 87 (FJ536664.1) & Astraeus hygrometricus \\
\hline $\mathrm{CN} 4$ & 368 & $99 \%$ & 90 (JF746992.1) & Termitomyces sp. \\
\hline CN 5 & 463 & $93 \%$ & 99 (GU001667.1) & Termitomyces sp. \\
\hline CN 6 & 161 & $67 \%$ & $82(\mathrm{EF} 421077.1)$ & Termitomyces microcarpus \\
\hline $\mathrm{CN} 7$ & 177 & $90 \%$ & 76 (JF746993.1) & Termitomyces sp. \\
\hline $\mathrm{CN} 8$ & 359 & $100 \%$ & 100 (JN086680.1) & Volvariella volvacea \\
\hline
\end{tabular}

sequences. Codon positions included were 1 st $+2 \mathrm{nd}+3 \mathrm{rd}+$ noncoding. All positions containing gaps and missing data were eliminated. There were a total of 102 positions in the final data set. Evolutionary analyses were conducted in Molecular Evolutionary Genetics Analysis 5 (MEGA5) [23].

\section{Results}

The size of the DNA of 8 mushroom samples was around $15 \mathrm{~kb}$. The PCR amplification products (Figure 1) showed that $\mathrm{CN} 1$ and 2 gave around 200 to $250 \mathrm{bp}$ amplified band, while CN 3 and 6 had 300 bp amplified band. CN 4, 5, and 7 documented a band around $500 \mathrm{bp}$, while $\mathrm{CN} 8$ showed $400 \mathrm{bp}$ band. These PCR products were gel purified, run in $1 \%$ agarose gel, and processed for nucleotide sequencing.

The partial nucleotide sequences (Table 2) of 8 samples were obtained and analyzed for Basic Local Alignment Search Tool (BLAST) search program (National Center for Biotechnology Information (NCBI) site) against the whole GenBank data base of nucleotide sequences (using ClustalW software) for identification. Each PCR product was sequenced using forward and reverse primers and both were used for BLAST. The BLAST result is presented in Table 3. Based on \% identity, mushrooms may be identified as follows: CN 1-Amanita hemibapha [family: Amanitaceae; \% identity 99 (JX844716.1)]; CN 2-Amanita sp. [\% identity 98 (JX844763.1)]; CN 3-Astraeus hygrometricus [Family: Diplocystaceae; \% identity 87 (FJ536664.1)]; CN 4-Termitomyces sp. [Family: Lyophyllaceae; \% identity 90 (JF746992.1)]; CN 5-Termitomyces sp. [\% identity 99 (GU001667.1)]; CN 6-T. microcarpus [\% identity 82 (EF421077.1)]; CN 7-Termitomyces sp. [\% identity 76 (JF746993.1)]; and CN 8-Volvariella volvacea [Family: Pluteaceae; \% identity 100 (JN086680.1)]. Out of 8 samples, 4 belong to Termitomyces spp. of which only 1 could be identified up to species level from the available GenBank data base. Molecular identification of the mushroom samples corroborated morphological identification of the samples up to genus level (Figures 2(a)-2(h)).

Phylogenetic tree (Figure 3) constructed revealed a close relationship between $\mathrm{CN} 1$ and 2 (A. hemibapha and Amanita

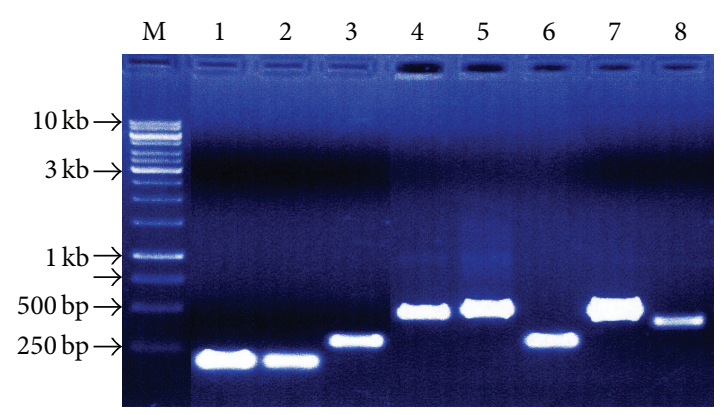

FIGURE 1: Gel purified PCR product of the field isolated mushroom samples (M marker lane, $1 \mathrm{~kb}$ ladder).

sp.), 4 and 5 (Termitomyces sp.), and 3 and 6 (Astraeus hygrometricus and T. microcarpus). CN 8 ( $V$. volvacea) showed close affinity with CN 1, 2, 4, and 5; however, CN 7 (Termitomyces sp.) showed distant relationship with other samples.

\section{Discussion}

The nucleotide sequences of 8 mushroom samples were blasted against available sequences from GenBank data base for identification. One sample, CN 8 (Volvariella sp.), matched $100 \%$ Indian sample $V$. volvacea, accession number JN086680.1, reported from Solan, Himachal Pradesh. On the other hand, the rest of the samples matched the samples that were reported from outside of India. However, CN 1 identified as A. hemibapha (pileus color: yellow) from GenBank data base matched morphologically the reported mushroom $A$. hemibapha (pileus color: white) by Roy and Samajpati [24] from Bankura district, West Bengal, adjoining to the current location of study. On the contrary, CN 2 was also identified as Amanita sp. that possessed white color pileus. Therefore, $\mathrm{CN} 1$ and 2 could be different Amanita species as evinced from nucleotide sequences. CN 6 was identified to be as $T$. microcarpus from the available sequence of GenBank data base ( $82 \%$ homology). CN 4 and 5 belonging to Termitomyces spp. seem to be of genetic lineage different from that of the other Termitomyces spp. (CN 6 and 7) as noted from the phylogenetic tree; however, all Termitomyces species were collected from the same locality. From molecular point of 


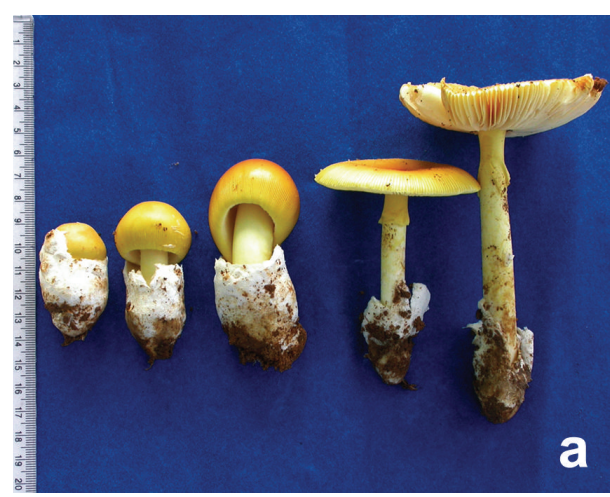

(a)

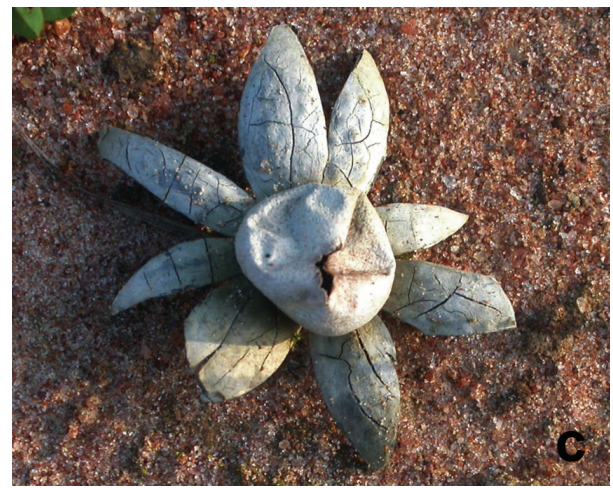

(c)

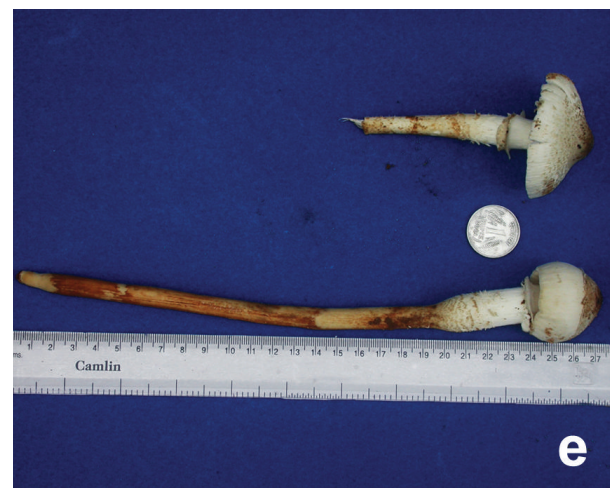

(e)

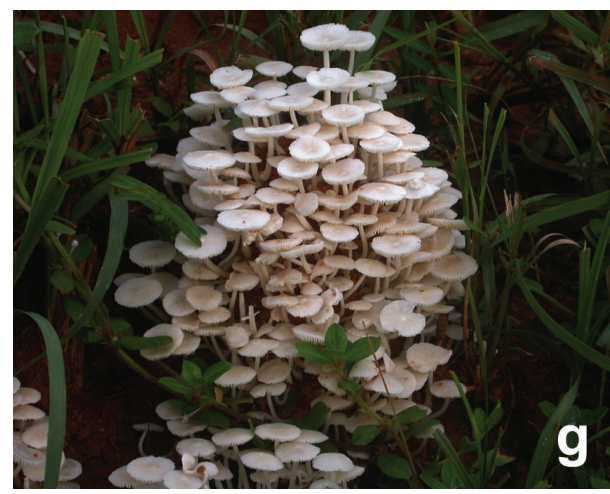

(g)

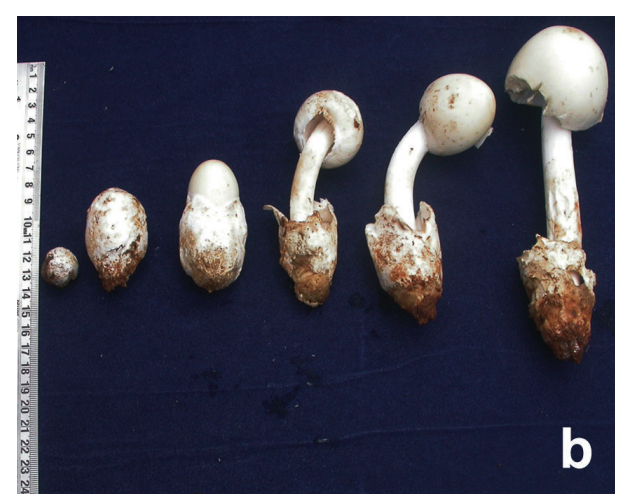

(b)

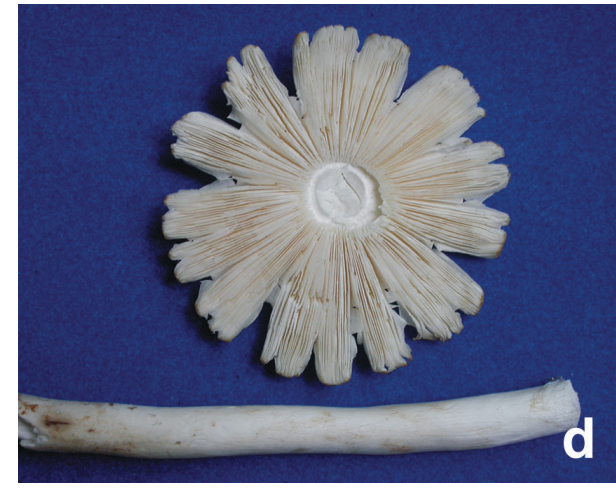

(d)

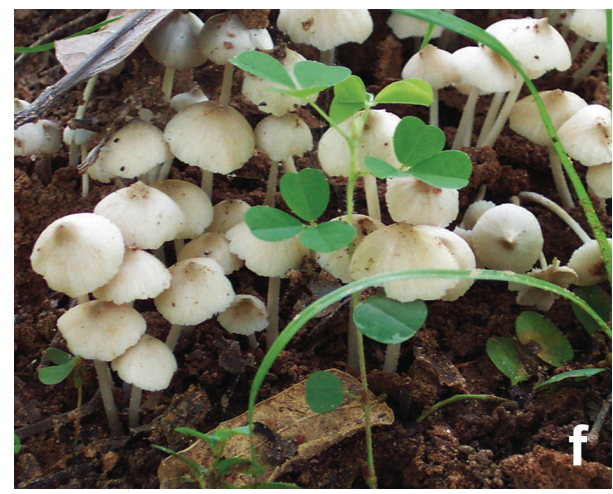

(f)

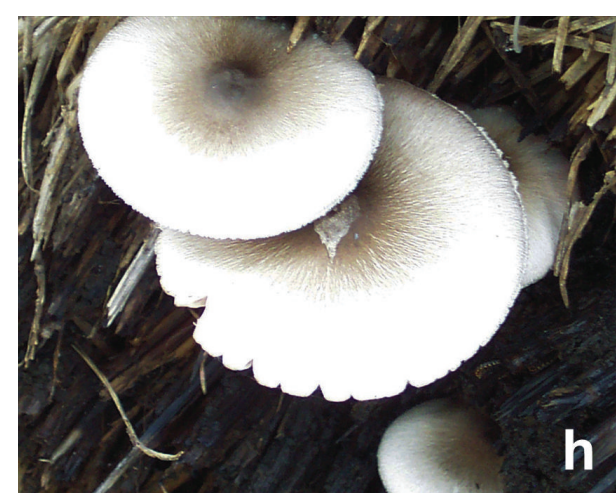

(h)

Figure 2: Fruit bodies of mushrooms. (a) Amanita hemibapha-CN 1. (b) Amanita sp.-CN 2. (c) Astraeus hygrometricus-CN 3. (d) Termitomyces sp.-CN 4. (e) Termitomyces sp.-CN 5. (f) T. microcarpus-CN 6. (g) Termitomyces sp.-CN 7. (h) Volvariella volvacea-CN 8. 


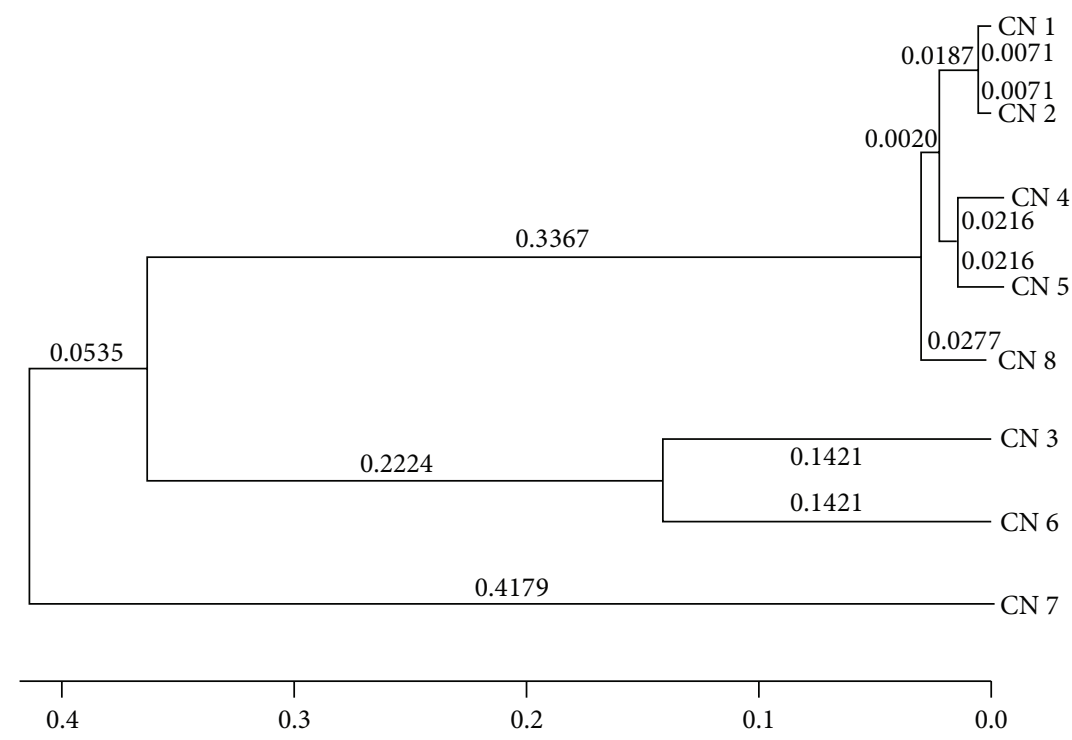

FIGURE 3: Phylogenetic tree showing relationship of mushroom samples.

view CN 4 and 5 were identified as Termitomyces spp., and these samples matched morphologically $T$. clypeatus and T. eurhizus [25], respectively. Tang et al. [26] also characterized Termitomyces species (T. longiradicatus, T. quilonensis, and T. poonensis) different morphologically from India. From phylogenetic tree, $V$. volvacea showed distinct relationship to A. hemibapha and Amanita sp. although the fungi belong to different families and therefore the finding is rather interesting from taxonomic point of view and may further be explored. The present study possibly suggests that GenBank data base for mushroom is not sufficiently rich in India. However, molecular characterization of 4 mushroom samples up to species level is performed and is essential and the provided nucleotide sequences of the rest of the samples may be relevant to GenBank data base for further exploration in the field.

Rajaratnam and Thiagarajan [11] extracted genomic DNA from the fruit body of wild mushroom and subjected it to nucleotide sequencing using ITS1 and ITS4 conserved primer stretches. The sequence was aligned using JukesCantor Correlated Distance model and the aligned sequence (559 bp) revealed $88 \%$ matched score with Perenniporia sp. (GQ982890.1). Dung et al. [27] characterized 6 Oyster mushroom samples based on both morphological and molecular data and found that both were corroborating to each other. Lee et al. [16] performed identification of 3 medicinal mushroom (Ganoderma lucidum, Coriolus versicolor, and Fomes fomentarius) species from Korea based on nuclear large subunit rDNA sequences. Nucleotide sequencing of Termitomyces albuminosus [28], Ganoderma lucidum [29], and Agaricus bisporus [30], among others was also performed.

\section{Conclusion}

Molecular identification of the fungal samples may enrich and provide additional information to mushroom biodiversity and GenBank data base resource aiding to molecular phylogenetic analysis. Further, identification knowledge may also be significant for human benefits.

\section{Acknowledgments}

The research is grant-aided by Science \& Society Division, Department of Science and Technology, Government of India. The authors sincerely acknowledge the kind help of Dr. Soma Chattopadhyay, Scientist, Institute of Life Sciences (Government of India), during work and preparation of the paper.

\section{References}

[1] S. T. Chang and P. G. Miles, "Mushroom biology-a new discipline," The Mycologist, vol. 6, pp. 64-65, 1992.

[2] T. N. Kaul, Introduction to Mushroom Science: Systematics, Oxford \& IBH Publishing, New Delhi, India, 1997.

[3] P. Manzi, L. Gambelli, S. Marconi, V. Vivanti, and L. Pizzoferrato, "Nutrients in edible mushrooms: an inter-species comparative study," Food Chemistry, vol. 65, no. 4, pp. 477-482, 1999.

[4] S. G. Jonathan and I. O. Fasidi, "Antimicrobial activities of two Nigerian edible macrofungi-Lycoperdonpusilum (Bat. Ex) and Lycoperdongigantum(Pers)," African Journal of Biomedical Research, vol. 6, pp. 85-90, 2003.

[5] O. O. Kuforiji, I. O. Fasidi, and S. A. Odunfa, "Nutritive value of Pleurotus tuberregium cultivated on different agro-industrial wastes," Nigerian Journal of Microbiology, vol. 17, pp. 68-70, 2003.

[6] J. Gbolagade and I. Fasidi, "Antimicrobial activities of some selected Nigerian mushrooms," African Journal of Biomedical Sciences, vol. 8, no. 2, pp. 83-87, 2005.

[7] T. Yaltirak, B. Aslim, S. Ozturk, and H. Alli, "Antimicrobial and antioxidant activities of Russula delica Fr.," Food and Chemical Toxicology, vol. 47, no. 8, pp. 2052-2056, 2009.

[8] L. Barros, M. Ferreira, B. Queirós, I. C. F. R. Ferreira, and P. Baptista, "Total phenols, ascorbic acid, $\beta$-carotene and lycopene 
in Portuguese wild edible mushrooms and their antioxidant activities," Food Chemistry, vol. 103, no. 2, pp. 413-419, 2007.

[9] D. Kumari, M. S. Reddy, and R. C. Upadhyay, "Nutritional composition and antioxidant activities of 18 different wild Cantharellus mushrooms of Northwestern Himalayas," Food Science and Technology International, vol. 17, no. 6, pp. 557-567, 2011.

[10] C. Manoharachary, K. Sridhar, R. Singh et al., "Fungal biodiversity: distribution, conservation and prospecting of fungi from India," Current Science, vol. 89, no. 1, pp. 58-71, 2005.

[11] S. Rajaratnam and T. Thiagarajan, "Molecular characterization of wild mushroom," European Journal of Experimental Biology, vol. 2, no. 2, pp. 369-373, 2012.

[12] G. G. Fonseca, E. A. Gandra, L. F. Sclowitz, A. P. A. Correa, J. A. J. Costa, and J. A. Levy, "Oyster mushrooms species differentiation through molecular markers RAPD," International Journal of Plant Breeding and Genetics, vol. 2, pp. 13-18, 2008.

[13] A. Pawlik, G. Janusz, J. Koszerny, W. Małek, and J. Rogalski, "Genetic diversity of the edible mushroom Pleurotus sp. by amplified fragment length polymorphism," Current Microbiology, vol. 65, no. 4, pp. 438-445, 2012.

[14] D. J. Royse, B. A. Bunyard, and M. S. Nicholson, "Molecular genetic analysis of diversity in populations of edible mushrooms," in Mushroom Biology and Mushroom Products, S. T. Chang, J. A. Buswell, and S. Chiu, Eds., pp. 49-54, The Chinese University Press, Hong Kong, 1993.

[15] L. Savard, P. Li, S. H. Strauss, M. W. Chase, M. Michaud, and J. Bousquet, "Chloroplast and nuclear gene sequences indicate Late Pennsylvanian time for the last common ancestor of extant seed plants," Proceedings of the National Academy of Sciences of the United States of America, vol. 91, no. 11, pp. 5163-5167, 1994.

[16] J. S. Lee, M. O. Lim, K. Y. Cho, J. H. Cho, S. Y. Chang, and D. H. Nam, "Identification of medicinal mushroom species based on nuclear large subunit rDNA sequences," Journal of Microbiology, vol. 44, no. 1, pp. 29-34, 2006.

[17] M. Nei, Molecular Evolutionary Genetics, Columbia University Press, New York, NY, USA, 1987.

[18] D. L. Largent and D. E. Stuntz, How to Identify Mushrooms to Genus I: Macroscopic Features, Mad River Press, Revised edition, 1986.

[19] S. K. Das, Morphological, biochemical and molecular characterization of some wild edible mushroom of Eastern Chotonagpur part of West Bengal [Ph.D. thesis], University of Kalyani, West Bengal, India, 2013.

[20] G. C. Graham, P. Mayers, and R. J. Henry, "A simplified method for the preparation of fungal genomic DNA for PCR and RAPD analysis," BioTechniques, vol. 16, no. 1, pp. 48-50, 1994.

[21] N. Saitou and M. Nei, "The neighbor-joining method: a new method for reconstructing phylogenetic trees," Molecular Biology and Evolution, vol. 4, no. 4, pp. 406-425, 1987.

[22] K. Tamura, M. Nei, and S. Kumar, "Prospects for inferring very large phylogenies by using the neighbor-joining method," Proceedings of the National Academy of Sciences of the United States of America, vol. 101, no. 30, pp. 11030-11035, 2004.

[23] K. Tamura, D. Peterson, N. Peterson, G. Stecher, M. Nei, and S. Kumar, "MEGA5: molecular evolutionary genetics analysis using maximum likelihood, evolutionary distance, and maximum parsimony methods," Molecular Biology and Evolution, vol. 28 , no. 10, pp. 2731-2739, 2011.

[24] A. Roy and N. Samajpati, "Agaricales of West Bengal. III," Indian Journal of Mycological Research, vol. 18, pp. 13-24, 1980.
[25] R. P. Purkayastha and A. Chandra, Manual of Indian Edible Mushrooms, pp. 12-225, Today and Tomorrow's Publication, New Delhi, India, 1985.

[26] B.-H. Tang, T.-Z. Wei, and Y.-J. Yao, “Type revision of three Termitomyces species from India," Mycotaxon, vol. 94, pp. 93$102,2005$.

[27] N. T. P. Dung, D. B. Tuyen, and P. H. Quang, "Morphological and genetic characteristics of oyster mushrooms and conditions effecting on its spawn growing," International Food Research Journal, vol. 19, no. 1, pp. 347-352, 2012.

[28] F. Yang, B. Xu, S. Zhao et al., "De novo sequencing and analysis of the termite mushroom (Termitomyces albuminosus) transcriptome to discover putative genes involved in bioactive component biosynthesis," Journal of Bioscience and Bioengineering, vol. 114, no. 2, pp. 228-231, 2012.

[29] S. Chen, J. Xu, C. Liu et al., "Genome sequence of the model medicinal mushroom Ganoderma lucidum," Nature Communications, vol. 3, article 913, 2012.

[30] E. Morin, A. Kohler, A. R. Baker et al., "Genome sequence of the button mushroom Agaricus bisporus reveals mechanisms governing adaptation to a humic-rich ecological niche," Proceedings of the National Academy of Sciences, vol. 109, no. 43, pp. 1750117506, 2012. 

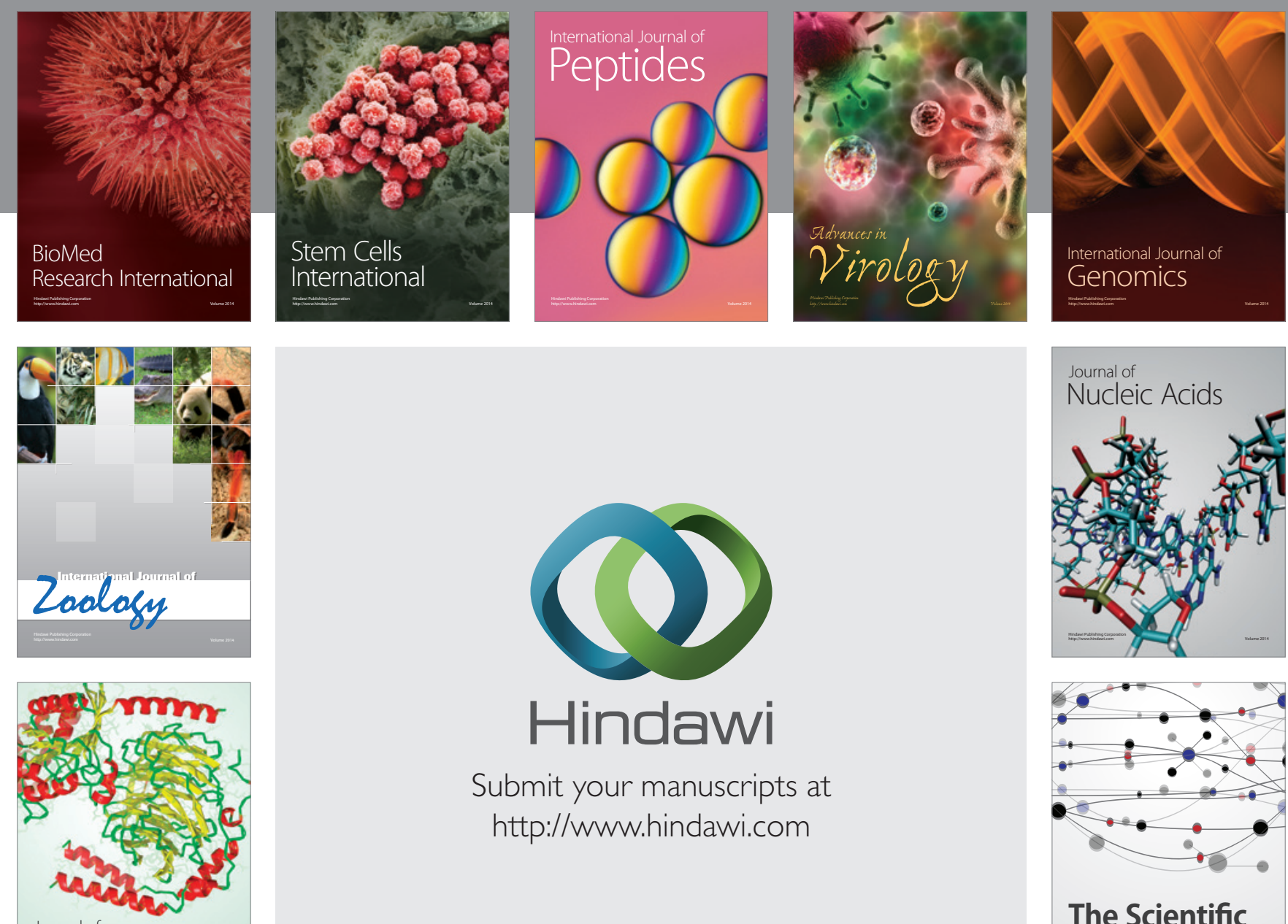

Submit your manuscripts at

http://www.hindawi.com

Journal of
Signal Transduction
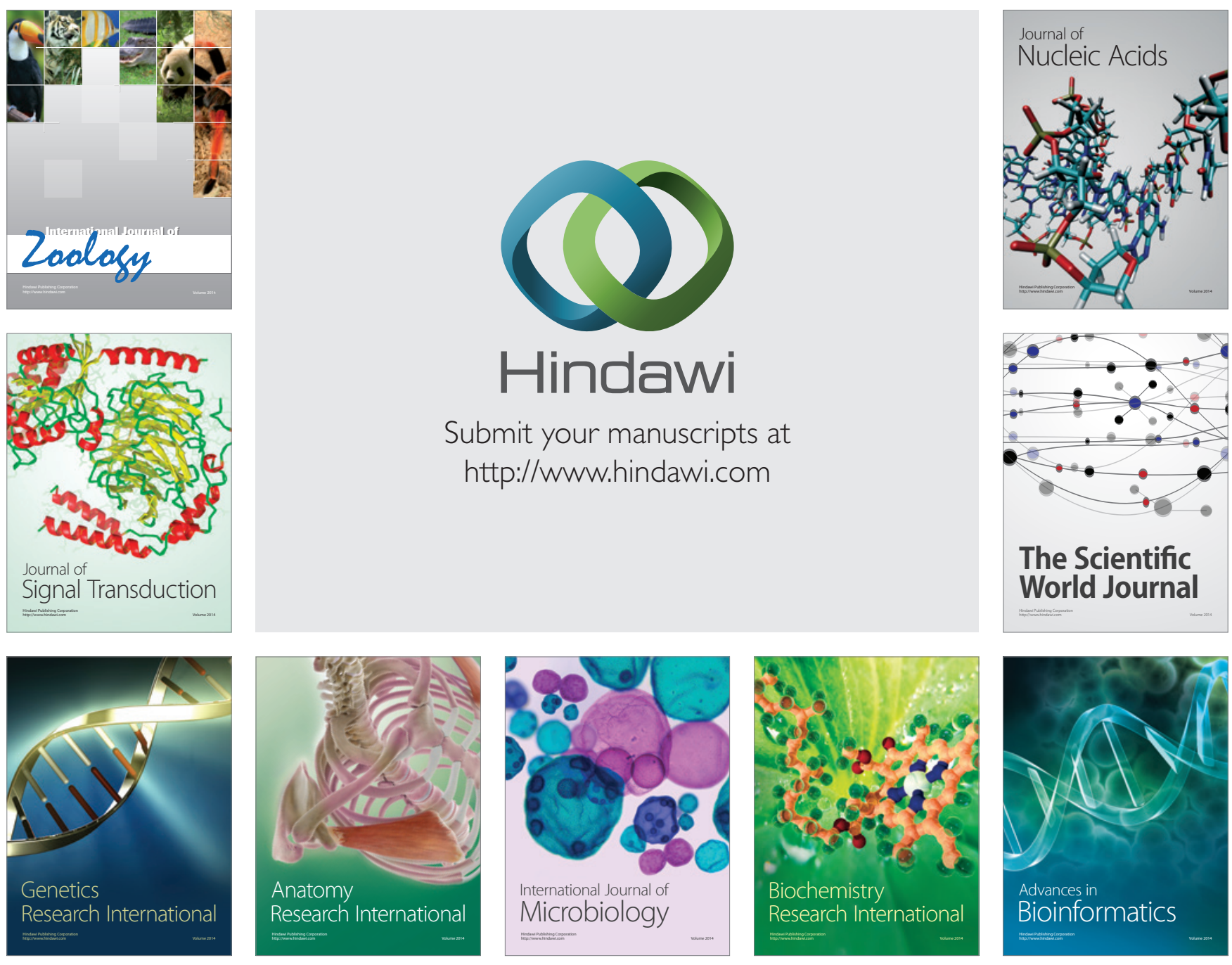

The Scientific World Journal
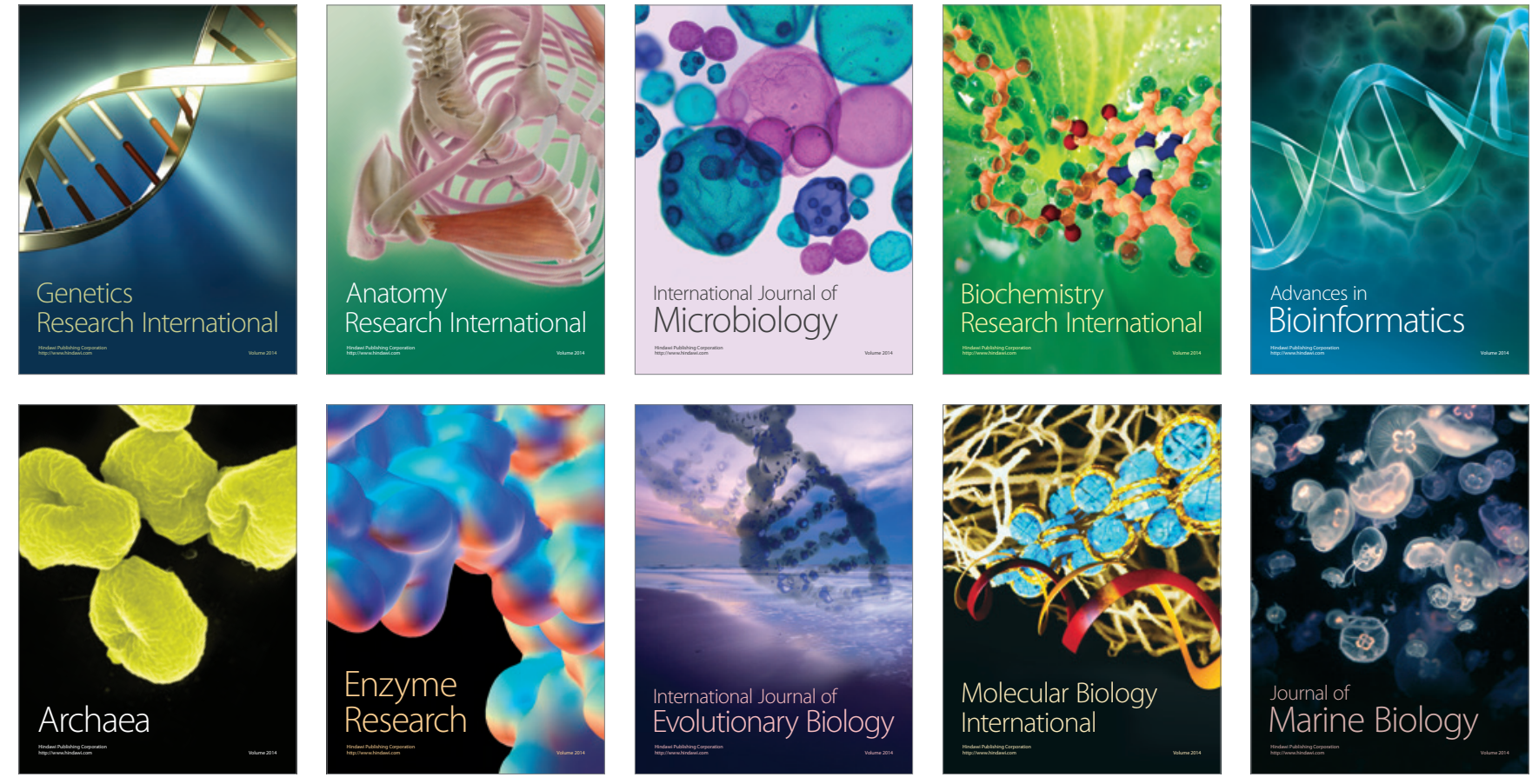